\title{
Habilidades interpessoais na atuação do psicólogo
}

\author{
Marina Bandeira \\ Maria Amélia Cesari Quaglia \\ Lucas Cordeiro Freitas \\ Amanda Monteiro de Sousa \\ Andréa Luciane Pires Costa \\ Marcela Mansur Pires Gomides \\ Pedro Baratti Lima \\ Universidade Federal de São João del Rei
}

\begin{abstract}
RESUMO
A habilidade de interagir com as pessoas é fundamental para o exercício da profissão de psicólogo. Estudos com estudantes de Psicologia, entretanto, apontaram déficits no seu repertório de habilidades interpessoais, tanto para alunos de início quanto de final do curso. Esses dados sugerem que os cursos de Psicologia não contemplam a formação dessas habilidades. Esta pesquisa investigou a opinião de profissionais de Psicologia sobre as habilidades interpessoais na sua atuação profissional. Participaram da pesquisa 74 psicólogos do interior de Minas Gerais, que responderam a um questionário sobre o grau de importância e de domínio de 51 habilidades interpessoais. Os resultados mostraram que, dentre estas, 39 foram consideradas de muita ou máxima importância. Obteve-se uma correlação significativa entre o grau de importância e de domínio das habilidades interpessoais. O grau de domínio mostrou-se inferior ao da importância atribuída às habilidades interpessoais. Houve diferença na ordem de importância atribuída às habilidades, em função da abordagem teórica e da formação acadêmica. Conclui-se que estas habilidades são importantes para a atuação profissional dos psicólogos, o que aponta para a necessidade de desenvolvê-las no curso de Psicologia.
\end{abstract}

Palavras-chave: habilidades interpessoais; psicólogos; atuação profissional.

\begin{abstract}
Social skills in psychologists' profession

The interpersonal skills are essential to the professional work of the psychologists. However, the results researches have shown deficits in the social skills repertoire of Psychology undergraduate students at the beginning and at the end of the course. This result suggests that Psychology undergraduate courses do not promote social skills development. This research investigated the opinion of Psychology professionals about the interpersonal skills in relation to their profession. A sample of 74 professionals of a medium town of Minas Gerais, Brazil, participated in this research, answering a questionnaire to evaluate the level of importance and competence of 51 interpersonal skills. The results showed that 39 of these skills were classified as high or maximum importance. There was a significant correlation between the levels of importance and the competence scores. The competence level reported by the subjects in each interpersonal skill was lower than the importance level attributed to the referred interpersonal skills. There were differences in the hierarchy of importance attributed to the skills, according to the theoretical orientation of the psychologists and their academic degree. It is concluded that the interpersonal skills are important for Psychology Professionals, pointing to the need to teach these skills in undergraduate Psychology courses.
\end{abstract}

Keywords: interpersonal skills; psychologists; undergraduate student.

A atuação profissional do psicólogo requer um repertório adequado de habilidades de comunicação interpessoal, que o capacite a lidar com as situações sociais inerentes ao exercício de sua profissão, nas diversas áreas de aplicação da Psicologia. A qualidade da relação interpessoal que o psicólogo estabelece 
com as pessoas, na sua atuação profissional, dependerá do seu desempenho social e, portanto, do seu repertório de habilidades sociais. Segundo Del Prette e Del Prette (2001), algumas profissões como, a do psicólogo, requerem habilidades técnicas que estão estreitamente mediadas pelas interações sociais e que foram denominadas de habilidades sociais profissionais, na literatura da área. Foram definidas, por estes autores, como aquelas habilidades "que atendem às diferentes demandas interpessoais do ambiente de trabalho, objetivando o cumprimento de metas, a preservação do bem-estar da equipe e o respeito aos direitos de cada um" (p. 89). Na psicologia, Falcone (2003) aponta pesquisas constatando, por exemplo, que terapeutas com maior grau da habilidade de empatia atingiram resultados significativamente melhores com seus clientes do que terapeutas com baixos escores nesta habilidade.

Entretanto, no ensino do curso de Psicologia, pouca ênfase é atribuída à formação dos alunos visando o desenvolvimento do repertório de habilidades sociais (Del Prette, 1978; Del Prette, Del Prette \& Correia, 1992). Conforme destaca Del Prette e Del Prette (2003), apesar de haver uma preocupação neste sentido, por parte de professores de cursos universitários e de supervisores no contexto das organizações, as habilidades interpessoais não tem sido abordada de forma sistemática. Esta tendência sugere implicitamente, pelo menos, duas explicações: que as habilidades necessárias para lidar com situações de interação social estão sendo consideradas como parte já existente no repertório dos alunos, portanto, sem necessidade de ser desenvolvida nos cursos ou, então, que a importância deste repertório de habilidades sociais tem sido subestimada ou considerada como relativamente pouco importante, comparativamente aos conhecimentos técnicos a serem ensinados no curso. Como o desenvolvimento deste repertório ocorre de foram assistemática, Del Prette e Del Prette (2001) o denominam de "currículo oculto".

Por outro lado, pesquisas (por exemplo, Del Prette, Del Prette \& Castelo Branco, 1992b) têm demonstrado que estudantes do curso de Psicologia muitas vezes não desenvolveram adequadamente este repertório, apresentando dificuldades em lidar com situações sociais. No estudo de Del Prette, Del Prette e Castelo Branco (1992b), algumas situações de interação social consideradas como particularmente difíceis foram identificadas, através de entrevistas individuais gravadas, com uma amostra de 12 estudantes, sendo 3 de cada uma das etapas do curso de Psicologia. Verifi- cou-se que as situações consideradas mais críticas pelos estudantes eram aquelas que requeriam uma reação ao comportamento indesejável de um interlocutor. Os interlocutores com quem tinham mais dificuldades eram pessoas estranhas e conhecidas, mais do que com familiares.

Bandeira e Quaglia (2005) investigaram, através de um questionário com perguntas abertas, as situações sociais relatadas espontaneamente como as mais incômodas, por uma amostra de 40 estudantes universitários, das áreas de Ciências Humanas (21) e de Ciências Exatas (19). Os resultados mostraram que os estudantes relataram espontaneamente se sentirem incomodados em 93 situações sociais, que foram classificadas em 17 categorias de situações requerendo habilidades sociais. As mais freqüentemente citadas foram as situações de asserção negativa ou de enfrentamento, que requerem expressar insatisfação e/ou solicitar mudança de comportamento e, em segundo lugar, expressar opinião/discordar. As situações sociais citadas pelos estudantes correspondiam, em sua grande maioria, às encontradas na literatura da área.

Utilizando um questionário fechado, contendo 40 situações sociais, Bandeira, Quaglia, Souza e Magalhães (2003) investigaram o grau de incômodo sentido nestas situações por uma amostra de 108 estudantes universitários, selecionados aleatoriamente de 8 cursos das áreas de Ciências Sociais e Exatas. As situações sociais que induziram maior grau de incômodo foram as que requeriam asserção negativa, caracterizada por atitudes de enfrentamento, tais como romper relacionamentos, lidar com pessoas que atendem mal em público, cobrar dinheiro ou objeto emprestado, enfrentar brigas ou discussões com familiares, ser cobrado por alguém. As situações com menor grau de incômodo foram as referentes a dar ou receber elogios e expressar sentimentos positivos.

A dificuldade de estudantes universitários em lidar com situações sociais pode ter repercussões em sua vida, comprometendo seu bem-estar psicológico e a sua qualidade de vida. Segundo Bryant e Trower (1974), as dificuldades de interação interpessoal de estudantes universitários podem estar relacionadas à elevada prevalência de distúrbios psicológicos observados nesta população-alvo. Em uma pesquisa realizada por estes autores, com 223 estudantes da Universidade de Oxford, utilizando um questionário com trinta situações sociais, constatou-se que três quartos da amostra relataram sentir dificuldade moderada em 5 a 6 situações sociais. Uma grande maioria dos estudantes $(99 \%)$ apresentava dificuldades leves, frente à 
maior parte das situações apresentadas no questionário. Os itens que foram considerados os mais difíceis se referiam a situações cotidianas, tais como sair para dançar, iniciar conversação e aproximar-se de outra pessoa. Segundo os autores, quando as tentativas de inserção no meio social são poucas ou mal sucedidas, elas tendem a provocar distúrbios psicossociais, que podem contribuir para o insucesso acadêmico e o abandono do curso.

Um estudo longitudinal, realizado por Segrin e Flora (2000), investigou a relação entre o déficit no repertório de habilidades sociais e a ocorrência de problemas psicossociais, em estudantes universitários da Universidade de Kansas, utilizando escalas de medida padronizadas. Os resultados mostraram uma relação significativa entre déficits de habilidades sociais e problemas psicossociais tais como depressão, ansiedade social, estresse e solidão. Além disso, aqueles indivíduos que possuíam um repertório adequado de habilidades sociais tinham também uma efetiva rede de suporte social, que favorecia o bem-estar psicológico e a qualidade de vida, protegendo-os contra problemas de saúde mental, nos momentos de estresse. Segundo os autores, as pessoas que possuem um repertório bem elaborado de habilidades sociais podem ter mais sucesso em suas vidas, tanto profissional quanto afetiva, o que pode diminuir os efeitos negativos dos momentos estressantes que venham a enfrentar.

Com base nesta preocupação com problemas de interação social e sua repercussão na vida dos estudantes universitários, Del Prette (1978) promoveu um treino assertivo com sete alunos do curso de Psicologia, demonstrando que estas habilidades podem ser desenvolvidas. $\mathrm{O}$ treino enfocou a discriminação das consequiências das respostas adequadas e inadequadas, mudança perceptual de si mesmo, treino de respostas alternativas, discriminação da própria resposta e do(s) $\mathrm{Sd}(\mathrm{s})$ ambientais. Era feita uma observação semanal dos alunos em relação às suas próprias condutas e um relato avaliativo pelos elementos do grupo, tendo sido encerrado o treinamento ao se atingir a adequação das respostas dos alunos, avaliada por auto e heteroavaliações. Os resultados mostraram uma melhora no relacionamento interpessoal, estabelecimento de situações mais viáveis a problemas pessoais e diminuição do nível de ansiedade diante de dificuldades sociais. Corroborando esta pesquisa, Del Prette e Del Prette (2003) obtiveram resultados igualmente positivos, em um outro programa de treinamento de habilidades sociais, que incluía duas sessões semanais, num total de 15 sessões, realizadas com dez estudantes univer- sitários de Ciências Exatas. Entretanto, apesar dos resultados positivos usualmente obtidos nos programas de treinamento das habilidades sociais, estas intervenções são raramente integradas aos cursos de Psicologia.

Embora as pesquisas tenham constatado que os estudantes sentem considerável grau de incômodo em lidar com algumas situações sociais e que estas dificuldades podem afetar seu bem-estar psicológico, os cursos de graduação não parecem estar promovendo o desenvolvimento das habilidades destes estudantes de lidar com estas situações. Del Prette, Del Prette e Correia (1992) encontraram resultados que apontam neste sentido, ao estudarem 218 estudantes universitários, de início e término, dos cursos de Serviço Social, Engenharia Mecânica e Psicologia, aplicando um questionário fechado com treze situações sociais. Os resultados mostraram que a maioria dos alunos, tanto de início quanto de término dos cursos, relataram sentir um alto incômodo em, pelo menos, seis das treze situações descritas no questionário. A semelhança observada entre os alunos de início e término dos cursos demonstrou que nenhum dos cursos estudados promoveu um aumento do repertório de habilidades sociais, embora uma conclusão mais definitiva a este respeito exigisse um estudo longitudinal, com uma mesma amostra de sujeitos. No caso do curso de Psicologia, os autores concluíram que os alunos de final de curso são mais sensíveis às situações sociais descritas, embora não apresentem respostas de maior competência social, comparativamente aos alunos de início de curso.

Estes mesmos resultados foram confirmados em uma outra pesquisa, focalizando especificamente o curso de Psicologia, onde alunos de início e término foram comparados (Del Prette, Del Prette \& Castelo Branco, 1992a). Foram avaliadas a incidência, o incômodo, a emissão da resposta indicadora de competência social e a satisfação que os alunos apresentavam com a resposta emitida, em 13 situações sociais listadas em um questionário, respondido por 79 estudantes. Os resultados mostraram que, nas dimensões estudadas, ocorreram semelhanças entre alunos de início e término do curso de Psicologia, exceto na dimensão de incômodo diante de cada situação. Concluiu-se que o curso não promoveu aquisição de competência social, pois os alunos do término do curso eram apenas mais sensíveis diante das situações críticas de interação social, mas não apresentavam maior competência social.

Embora haja evidência de que o curso de graduação não promova o desenvolvimento das habilidades de lidar com situações de interação social, foi obser- 
vado que os psicólogos atuantes em sua profissão, entretanto, consideram importantes estas habilidades para o bom desempenho de suas funções. Este foi o resultado da pesquisa de Del Prette, Del Prette, Barham e Reis (2000), na qual se investigou a opinião de uma amostra de 76 profissionais graduados em Psicologia, que trabalhavam em diferentes campos profissionais. A maioria era do sexo feminino e tinha algum curso de pós-graduação. Os psicólogos responderam um questionário, classificando 33 habilidades sociais, em uma escala tipo Likert de 5 pontos, em termos de sua importância para a profissão e em termos do domínio que eles possuíam destas habilidades. Todas as habilidades sociais foram consideradas pelos psicólogos como muito importantes ou com o máximo de importância. Com relação ao domínio, os escores estiveram sempre abaixo dos obtidos com a escala de importância.

As médias mais altas de valorização das habilidades sociais ocorreram nos campos da clínica, organização, escolar, saúde, enquanto que as médias mais baixas ocorreram junto aos profissionais da docência. Os dois itens de maior importância para a atuação do psicólogo, em todos os campos, foram: ouvir o outro e recusar pedidos abusivos. Os dois itens mais valorizados por, pelo menos, três dos cinco campos de atuação, foram: fazer e responder perguntas e expressar empatia. Os autores concluíram que os profissionais de psicologia reconhecem a importância de um repertório interpessoal elaborado, como parte da competência profissional do psicólogo. Entretanto, eles também reconheceram que certas habilidades, tidas como de maior importância para sua atuação, ainda não fazem parte dos seus repertórios. Estes resultados, porém, foram obtidos no contexto de uma única pesquisa e a amostra utilizada foi composta de profissionais que participavam de um congresso, o que pode constituir uma amostra particular de psicólogos. Há, portanto, uma carência de pesquisas que possam corroborar ou não os resultados encontrados sobre a importância e domínio das habilidades sociais, do ponto de vista dos psicólogos atuantes nesta área.

Visando aprofundar a investigação sobre a opinião dos profissionais de Psicologia sobre a importância das habilidades sociais para a atuação na profissão, o objetivo desta pesquisa foi o de fazer um levantamento sobre esta temática em uma nova amostra de psicólogos de uma outra região do país.

\section{MÉTODO}

\section{Participantes}

Participaram desta pesquisa 74 psicólogos, com registro no CRP, que atuavam em uma cidade de porte médio do interior de Minas Gerais. Os participantes foram selecionados a partir de uma lista concedida pelo CRP-04. Todos os psicólogos incluídos nesta lista foram contatados, mas somente os que estavam atuando na profissão participaram da pesquisa. A idade média dos participantes foi de 38,54 anos, sendo que $83,80 \%$ eram do sexo feminino e $16,20 \%$ do sexo masculino.

Classificando-os por área de atuação profissional, observou-se que $67,60 \%$ dos participantes trabalhavam na área clínica, 16,20\% na área de saúde, 5,40\% na área escolar, 5,40\% em docência, 2,70\% na área organizacional e do trabalho e $2,70 \%$ indicaram que trabalhavam em outras áreas não especificadas. Com relação às abordagens teóricas, 34,20\% dos participantes relataram que adotavam as abordagens Humanista, Existencial, Fenomenológica, Gestalt e combinações destas abordagens, 27,40\% dos participantes adotavam a abordagem Psicanalista, 16,40\% adotavam as abordagens Comportamental $(8,00 \%)$ e Cognitivo-comportamental (4,00\%), 13,70\% adotavam a abordagem eclética e $8,20 \%$ dos participantes relataram que adotavam outras abordagens, tais como Sistêmica, Estratégica, Logoterapia e Jungiana.

\section{Instrumento}

Foi elaborado um questionário fechado com o objetivo de avaliar o grau de importância relativa atribuída pelos participantes a uma série de habilidades interpessoais relevantes para a atuação profissional em Psicologia, assim como o grau de domínio que eles possuíam destas habilidades. O questionário era composto por 51 habilidades a serem avaliadas, em termos de uma escala tipo Likert de 5 pontos, na qual 1 representava o valor mínimo de importância ou de domínio na habilidade e 5 representava o valor máximo. $\mathrm{O}$ questionário incluía ainda questões de identificação geral dos participantes. Nesta parte, eram solicitadas informações relativas à atuação profissional, formação acadêmica e dados pessoais dos psicólogos.

Este questionário foi elaborado, com base em três fontes de informação: o inventário desenvolvido por Del Prette e cols. (2000), dados sobre as categorias de habilidades sociais encontradas na literatura da área 
(Caballo, 2003; Del Prette \& Del Prette, 1999; Ouellet e LAbbé, 1986) e entrevistas realizadas com 5 profissionais de Psicologia, visando colher informações sobre as habilidades mais relevantes para serem incluídas no questionário. Durante estas entrevistas, os profissionais opinaram sobre as questões presentes no questionário e sugeriram novas habilidades a serem incluídas.

\section{Procedimento}

O questionário foi aplicado, individualmente, na amostra de profissionais descrita acima, por cinco estagiários de pesquisa. Os profissionais eram contatados por telefone e, neste contato inicial, os objetivos do projeto de pesquisa eram esclarecidos e era solicitada a sua participação. Em seguida, eram marcados um dia e um horário, em função da disponibilidade do participante, para que os estagiários lhe entregassem o questionário.

Em função da falta de tempo dos profissionais, os estagiários não estiveram presentes no momento do preenchimento do questionário. Eram marcados outro dia e horário para que fossem recolhidos os questionários respondidos pelos participantes.

Os dados coletados foram computados e analisados por meio do programa SPSS-PC (Statistical Program for the Social Sciences), versão 7.5.

Foi realizada uma análise estatística descritiva, em termos de médias e porcentagens dos graus de importância e de domínio das habilidades interpessoais avaliadas. Foi utilizado também o teste " $\mathrm{t}$ " de Student para verificar se havia diferenças significativas entre os dados de importância e de domínio das habilidades. Foi feita ainda uma análise estatística paramétrica, Análise Discriminante, para comparação entre subgrupos da amostra. Para isto, foram comparados os subgrupos que diferiam em termos da formação acadêmica (graduação e pós-graduação), tempo de atuação (grupo com menos de 10 anos e grupo com mais de 10 anos de atuação) e abordagem teórica (comportamental, cognitivo-comportamental, psicanalítica, humanista, existencial, fenomenológica, gestalt, ecléticas e outras abordagens). Não foram comparados os subgrupos referentes às diferentes áreas de atuação profissional (clínica, escolar etc.), devido a uma grande concentração de psicólogos na área clínica e ao número muito reduzido nas demais áreas.

Como este questionário não foi submetido a um estudo de suas propriedades psicométricas, portanto, não tendo sido identificados os fatores ou sub-escalas de habilidades que o compõem, não foi possível fazer análises estatísticas para investigar diferenças na amostra com relação a sub-categorias de habilidades.

\section{RESULTADOS}

Os resultados obtidos na presente pesquisa mostraram que, dentre as 51 habilidades avaliadas, 39 foram consideradas de muita ou máxima importância para a atuação profissional do psicólogo. Além disso, os participantes relataram que tinham muito domínio de 29 das habilidades descritas no questionário.

Houve uma diferença significativa entre o grau de importância e o grau de domínio das habilidades ( $\mathrm{t}=$ $2,63 ; p<0,05)$. Os escores de grau de domínio das habilidades estavam abaixo dos escores de importância, ou seja, os psicólogos consideraram que não dominavam estas habilidades no mesmo grau em que as valorizavam.

A Tabela 1 apresenta as médias e desvios-padrão referentes ao grau de importância atribuída pelos psicólogos às habilidades interpessoais, em ordem decrescente.

Tabela 1: Médias e desvios-padrão dos escores de importância das habilidades de comunicação interpessoal, em ordem decrescente

\begin{tabular}{lcc}
\hline Habilidades & MÉDIA & $\begin{array}{c}\text { DESVIO } \\
\text { PADRÃO }\end{array}$ \\
\hline 28. Ouvir, com atenção, a fala da outra pessoa & 4,79 & 0,64 \\
48. Observar, com atenção, no outro, expressões verbais relevantes & 4,66 & 0,72 \\
06. Recusar pedidos abusivos & 4,64 & 0,81 \\
42. Ajudar o outro a identificar, nomear e expressar seus sentimentos & 4,58 & 0,74 \\
49. Relacionar-se com profissionais de outras áreas & 4,55 & 0,74 \\
39. Expor, com clareza e objetividade, conteúdos relevantes ao trabalho desenvolvido & 4,54 & 0,76 \\
12. Expressar empatia (solidarizar-se com os sentimentos do outro) & 4,54 & 0,79
\end{tabular}


144 Marina Bandeira; Maria Amélia Cesari Quaglia; Lucas Cordeiro Freitas; Amanda Monteiro de Sousa; Andréa Luciane Pires Costa; Marcela Mansur Pires Gomides \& Pedro Baratti Lima

47. Dizer não a solicitações que você não pode ou não quer atender

$4,52 \quad 0,83$

51. Observar, com atenção, no outro, expressões não-verbais relevantes

$4,51 \quad 0,81$

37. Demonstrar firmeza nas opiniões e decisões tomadas

$4,51 \quad 0,74$

21. Iniciar adequadamente uma conversação com outra pessoa

$4,47 \quad 0,83$

36. Responder, de forma adequada, às perguntas do interlocutor

$4,47 \quad 0,81$

34. Encerrar uma conversação de forma adequada

$4,47 \quad 0,83$

31. Fazer perguntas relevantes de acordo com as condições da interação

$4,47 \quad 0,91$

44. Reavaliar as decisões e atitudes tomadas, quando pertinente

$4,45 \quad 0,81$

24. Incentivar o outro no decorrer do trabalho desenvolvido

$4,43 \quad 0,92$

19. Fornecer feedback positivo(descrever aspectos adequados do desempenho do outro)

$4,43 \quad 0,95$

41. Fazer relações entre diferentes conteúdos da fala do interlocutor

$4,40 \quad 0,84$

40. Interpretar a fala do outro

$4,39 \quad 0,85$

27. Desculpar-se, quando for necessário

$4,32 \quad 1,00$

46. Manter uma conversação adequadamente

$4,32 \quad 1,07$

22. Lidar com críticas justas

15. Trabalhar cooperativamente em grupo

$4,29 \quad 1,04$

23. Coordenar atividade grupal

$4,27 \quad 0,99$

$4,27 \quad 0,99$

03. Estabelecer relações amistosas

09. Mediar conflitos entre indivíduos ou entre grupos

$4,25 \quad 0,96$

$4,22 \quad 1,11$

16. Elogiar aspectos positivos da outra pessoa

$4,21 \quad 1,06$

05. Intervir com o objetivo de acalmar o outro

$4,18 \quad 1,02$

29. Negociar soluções que envolvem interesses mútuos

$4,17 \quad 1,05$

10. Controlar seus sentimentos negativos

$4,16 \quad 0,97$

13. Controlar aspectos não verbais de sua comunicação (ex: expressão facial, postura)

4,14

4,13

30. Conduzir a direção de uma conversação

20. Controlar aspectos formais da própria fala (ex:modulação, fluência)

4,13

32. Lidar com críticas injustas

4,13

33. Reformular com outras palavras o conteúdo da fala do outro (parafrasear)

4,08

50. Utilizar conteúdos de humor em situações apropriadas

4,08

07. Expressar sua opinião para um indivíduo ou para grupos

4,04

4,04

01. Falar em público (ex: palestras, seminários)

4,02

25. Fornecer feedback negativo(descrever aspectos inadequados do desempenho do outro)

3,98

3,93

14. Defender propostas ou idéias

3,90

38. Justificar-se quando necessário

3,86

02. Expressar seus sentimentos positivos (ex: alegria, satisfação)

1,05

26. Resumir o conteúdo do discurso do interlocutor ao longo de uma conversação

3,82

11. Expor fatos que são desagradáveis para o interlocutor

3,67

3,64

04. Controlar seus sentimentos positivos

3,62

35. Solicitar mudanças de comportamento do outro

17. Solicitar favores, quando necessário

3,60

3,60

3,44

3,20

08. Expressar seus sentimentos negativos ( ex: aborrecimento, tristeza)

2,48

0,98

1,08

1,08

1,10

1,10

0,96

1,14

0,94

1,14

1,10

1,19

1,17

1,05

1,12

1,22

1,15

1,27

1,34

1,24

1,41

45. Auto-revelar-se (falar de si para a outra pessoa)

1,30

Pode-se observar, na Tabela 1, que as quatro habilidades consideradas como as mais importantes para a atuação dos psicólogos foram: "Ouvir, com atenção a fala da outra pessoa" $(4,79)$, "Observar, com atenção, expressões verbais relevantes" $(4,66)$, "Recusar pedidos abusivos" $(4,64)$ e "Ajudar o outro a identificar os seus sentimentos" $(4,58)$. Somente 12 habilidades foram consideradas com grau de importância abaixo de 4,00 .

A Tabela 2 apresenta as médias e desvios-padrão referentes ao grau de domínio das habilidades pelos psicólogos, em ordem decrescente. 
Tabela 2: Médias e desvios-padrão dos escores de domínio das habilidades de comunicação interpessoal, em ordem decrescente

\begin{tabular}{|c|c|c|}
\hline Habilidades & MÉDIA & $\begin{array}{c}\text { DESVIO } \\
\text { PADRÃO }\end{array}$ \\
\hline 28. Ouvir, com atenção, a fala da outra pessoa & 4,67 & 0,55 \\
\hline 12. Expressar empatia (solidarizar-se com os sentimentos do outro) & 4,37 & 0,71 \\
\hline 48. Observar, com atenção, no outro, expressões verbais relevantes & 4,36 & 0,73 \\
\hline 06. Recusar pedidos abusivos & 4,35 & 1,01 \\
\hline 21. Iniciar adequadamente uma conversação com outra pessoa & 4,33 & 0,66 \\
\hline 42. Ajudar o outro a identificar, nomear e expressar seus sentimentos & 4,32 & 0,72 \\
\hline 19. Fornecer feedback positivo (descrever aspectos adequados do desempenho do outro) & 4,28 & 0,78 \\
\hline 51. Observar, com atenção, no outro, expressões não verbais relevantes & 4,27 & 0,81 \\
\hline 03. Estabelecer relações amistosas & 4,24 & 0,75 \\
\hline 24. Incentivar o outro no decorrer do trabalho desenvolvido & 4,22 & 0,82 \\
\hline 15. Trabalhar cooperativamente em grupo & 4,21 & 0,79 \\
\hline 27. Desculpar-se, quando for necessário & 4,20 & 1,03 \\
\hline 34. Encerrar uma conversação de forma adequada & 4,18 & 0,80 \\
\hline 47. Dizer não a solicitações que você não pode ou não quer atender & 4,17 & 0,80 \\
\hline 02. Expressar seus sentimentos positivos (ex: alegria, satisfação) & 4,16 & 0,75 \\
\hline 49. Relacionar-se com profissionais de outras áreas & 4,14 & 0,83 \\
\hline 40. Interpretar a fala do outro & 4,14 & 0,83 \\
\hline 37. Demonstrar firmeza nas opiniões e decisões tomadas & 4,14 & 0,87 \\
\hline 16. Elogiar aspectos positivos da outra pessoa & 4,13 & 0,81 \\
\hline 46. Manter uma conversação adequadamente & 4,13 & 1,01 \\
\hline 31. Fazer perguntas relevantes de acordo com as condições da interação & 4,12 & 0,87 \\
\hline 44. Reavaliar as decisões e atitudes tomadas, quando pertinente & 4,10 & 0,86 \\
\hline 36. Responder, de forma adequada, às perguntas do interlocutor & 4,08 & 0,85 \\
\hline 05. Intervir com o objetivo de acalmar o outro & 4,06 & 0,86 \\
\hline 41. Fazer relações entre diferentes conteúdos da fala do interlocutor & 4,05 & 0,84 \\
\hline 07. Expressar sua opinião para um indivíduo ou para grupos & 4,05 & 0,84 \\
\hline 39. Expor, com clareza e objetividade, conteúdos relevantes ao trabalho desenvolvido & 4,05 & 0,79 \\
\hline 50. Utilizar conteúdos de humor em situações apropriadas & 4,02 & 0,84 \\
\hline 29. Negociar soluções que envolvem interesses mútuos & 4,01 & 0,98 \\
\hline 14. Defender propostas ou idéias & 3,98 & 1,02 \\
\hline 22. Lidar com críticas justas & 3,97 & 0,97 \\
\hline 30. Conduzir a direção de uma conversação & 3,93 & 1,07 \\
\hline 38. Justificar-se quando necessário & 3,91 & 1,06 \\
\hline 33. Reformular com outras palavras o conteúdo da fala do outro (parafrasear) & 3,90 & 0,95 \\
\hline 10. Controlar seus sentimentos negativos & 3,89 & 0,95 \\
\hline 09. Mediar conflitos entre indivíduos ou entre grupos & 3,86 & 0,91 \\
\hline 43. Solicitar ao outro suas impressões sobre o trabalho que está sendo realizado & 3,86 & 1,01 \\
\hline 23. Coordenar atividade grupal & 3,82 & 1,05 \\
\hline 26. Resumir o conteúdo do discurso do interlocutor ao longo de uma conversação & 3,79 & 0,93 \\
\hline 11. Expor fatos que são desagradáveis para o interlocutor & 3,74 & 0,95 \\
\hline 20. Controlar aspectos formais da própria fala (ex: modulação, fluência) & 3,72 & 0,89 \\
\hline 08. Expressar seus sentimentos negativos ( ex: aborrecimento, tristeza) & 3,72 & 1,10 \\
\hline 13. Controlar aspectos não verbais de sua comunicação (ex:expressão facial, postura) & 3,72 & 1,03 \\
\hline 04. Controlar seus sentimentos positivos & 3,64 & 1,05 \\
\hline 01. Falar em público (ex: palestras, seminários) & 3,60 & 0,96 \\
\hline 25. Fornecer feedback negativo(descrever aspectos inadequados do desempenho do outro) & 3,58 & 1,14 \\
\hline 18. Discordar da opinião do outro & 3,56 & 1,04 \\
\hline 35. Solicitar mudanças de comportamento do outro & 3,55 & 1,16 \\
\hline 17. Solicitar favores, quando necessário & 3,55 & 1,16 \\
\hline 32. Lidar com críticas injustas & 3,55 & 1,11 \\
\hline 45. Auto-revelar-se (falar de si para a outra pessoa) & 3,05 & 1,43 \\
\hline
\end{tabular}


As quatro habilidades que os psicólogos consideraram ter maior domínio na sua atuação profissional foram: "Ouvir, com atenção, o outro" $(4,67)$, "Expressar empatia (solidarizar-se com os sentimentos do outro), (4,37),"Observar expressões verbais relevantes" $(4,36)$ e "Recusar pedidos abusivos" $(4,35)$. Vinte e duas habilidades foram consideradas com grau de domínio abaixo de 4,00.

Com relação aos resultados da Análise Discriminante, não foram encontradas diferenças significativas, entre os subgrupos de sujeitos com diferentes tipos de formação (graduação e pós-graduação), tempo de atuação (menos de 10 anos e mais de 10 anos) e abordagens teóricas diversas. A ordem de importância atribuída às habilidades foi ligeiramente diferente em função destas variáveis, embora não estatisticamente significativas. Abaixo, será apresentada, portanto, apenas uma análise descritiva destes resultados.

Com relação à importância atribuída às habilidades, em função da formação dos psicólogos, os resultados indicaram que os que possuíam apenas graduação consideraram como mais importantes as seguintes habilidades, em ordem decrescente de suas médias: "Recusar pedidos abusivos" $(4,72)$, "Ouvir, com atenção, a fala da outra pessoa" $(4,72)$, "Observar expressões verbais relevantes" $(4,72)$, "Observar expressões não-verbais relevantes" $(4,68)$. Para os psicólogos com pós-graduação, as habilidades consideradas mais importantes foram as seguintes, em ordem decrescente de suas médias: "Ouvir, com atenção, a fala da outra pessoa" $(4,83)$, "Observar expressões verbais relevantes" (4,63), "Recusar pedidos abusivos' $(4,61)$, "Dizer não a solicitações que não pode atender" $(4,59)$.

No que se refere à importância atribuída às habilidades, em função do tempo de atuação dos psicólogos, os resultados mostraram que os que possuíam menos de 10 anos de atuação consideraram como mais importantes, em ordem decrescente, as seguintes habilidades: "Ouvir com atenção a fala da outra pessoa" $(4,83)$, "Observar expressões verbais relevantes" $(4,70)$, "Dizer não a solicitações que não pode atender" $(4,66)$ e "Fornecer feedback positivo" $(4,60)$. Os psicólogos com mais de 10 anos de atuação consideraram como mais importantes as seguintes habilidades, em ordem decrescente: "Ouvir, com atenção, a fala da outra pessoa" $(4,77)$, "Ajudar a identificar e expressar sentimentos" $(4,68)$, "Observar expressões verbais relevantes" $(4,63)$; "Demonstrar firmeza nas decisões tomadas" $(4,63)$.
Quanto à importância atribuída às habilidades em função da abordagem teórica, os resultados mostraram que o subgrupo dos psicólogos que adotavam as abordagens comportamental e cognitivo-comportamental citou como mais importantes, em ordem decrescente, as seguintes habilidades: "Observar expressões verbais relevantes" $(4,83)$, "Reavaliar as decisões e atitudes tomadas" $(4,83)$, "Recusar pedidos abusivos" $(4,83)$, "Ouvir, com atenção, a fala da outra pessoa" $(4,75)$. O subgrupo dos psicólogos que adotavam a abordagem psicanalítica considerou como mais importantes as seguintes habilidades: "Ouvir, com atenção, a fala da outra pessoa" $(4,90)$, "Dizer não a solicitações que não pode atender" $(4,80)$, "Interpretar a fala do outro" $(4,70)$, "Recusar pedidos abusivos" $(4,65)$.

Quanto ao subgrupo que adotava as abordagens humanista, existencial, fenomenológica e gestalt, as habilidades consideradas como mais importantes, em ordem decrescente, foram: "Recusar pedidos abusivos" $(4,80)$, "Ajudar a identificar e expressar sentimentos" (4,80), "Observar expressões verbais relevantes" $(4,76)$, "Ouvir com atenção a fala da outra pessoa" $(4,76)$. Os que adotavam uma abordagem eclética classificaram como mais importantes, em ordem decrescente, as seguintes habilidades: "Ajudar a identificar e expressar sentimentos" $(4,90)$, "Ouvir, com atenção, a fala da outra pessoa" $(4,90)$, "Observar expressões não-verbais relevantes" $(4,80)$, "Relacionar-se com profissionais de outras" $(4,80)$.

Alguns pontos de convergência foram identificados nos resultados. Duas habilidades constaram da lista das dez mais importantes para a atuação profissional, independentemente da abordagem teórica adotada pelos psicólogos. Estas habilidades foram: "Ouvir, com atenção, a fala da outra pessoa" e "Observar, com atenção, no outro, expressões verbais relevantes". Uma habilidade foi incluída entre as dez mais importantes, tanto pelos profissionais de abordagem comportamental, quanto pelos psicólogos humanistas e pelos psicanalistas. Trata-se da habilidade de "Recusar pedidos abusivos".

Com relação a habilidade de "Ajudar o outro a identificar, nomear e expressar seus sentimentos" e a habilidade de "Expor, com clareza e objetividade, conteúdos relevantes ao trabalho desenvolvido", ambas estiveram presentes entre as dez habilidades consideradas mais importantes pelos psicólogos que utilizavam as abordagens comportamental, humanista e eclética, mas não pelos psicanalistas. 
A habilidade "Expressar empatia" esteve presente entre as dez habilidades consideradas mais importantes pelos psicólogos que utilizavam as abordagens humanista e psicanálise, mas não pelos psicólogos de abordagem comportamental ou eclética. Já a habilidade de "Dizer não a solicitações que você não pode ou não quer atender" esteve presente entre as dez habilidades consideradas mais importantes nas abordagens comportamental, psicanálise e abordagem eclética.

As habilidades de "Observar, no outro, expressões não verbais relevantes" e "relacionar-se com profissionais de outras áreas" estiveram presentes entre as dez habilidades consideradas mais importantes pelos psicólogos que utilizam as abordagens humanista e eclética.

\section{DISCUSSÃO E CONCLUSÃO}

Os resultados obtidos na presente pesquisa confirmam os dados da única pesquisa encontrada especificamente sobre o grau de importância e de domínio das habilidades sociais, tal como avaliada por psicólogos atuantes na área (Del Prette e cols., 2000). Considerando a carência de dados sobre o assunto e a necessidade de sua confirmação por diferentes pesquisadores e amostras diversificadas, que é inerente à construção do conhecimento científico, os resultados da presente pesquisa serviram para corroborar e ampliar a generalidade dos dados obtidos por Del Prette e cols. (2000), na qual foi usado um questionário similar de habilidades sociais, com uma amostra de psicólogos de outra região do país.

Os resultados obtidos indicam que as habilidades sociais profissionais estudadas aqui foram consideradas, por uma amostra diversificada de psicólogos, como muito importantes para a atuação do psicólogo. A grande maioria das habilidades investigadas foram consideradas importantes, atingindo o ponto máximo ou próximo do máximo da escala de classificação de cinco pontos. Estes dados são similares aos obtidos por Del Prette e cols.(2000).

Dentre as habilidades estudadas, na presente pesquisa, as quatro consideradas pelos psicólogos como sendo as mais importantes para a atuação profissional em Psicologia, foram: ouvir, observar, recusar pedidos abusivos e ajudar o outro a identificar os seus sentimentos. Estes resultados corroboram os dados obtidos no estudo de Del Prette e cols. (2000), onde as duas habilidades interpessoais consideradas mais importantes para a atuação em Psicologia foram: ouvir o outro e recusar pedidos abusivos.
Nota-se a classificação de destaque que os psicólogos atribuíram à habilidade de ouvir com atenção, na presente pesquisa e no estudo de Del Prette e cols. (2000). Saber ouvir constitui uma habilidade básica, incluída em manuais de pesquisa e intervenção em habilidades sociais (Ouellet e L'Abbé, 1986; Caballo, 1996, 2003). A escuta ativa é considerada como componente importante e pré-requisito da habilidade de iniciar e manter uma conversação, segundo Caballo (1996). Constitui-se ainda em componente importante da habilidade de dar retroalimentação (feedback) ao interlocutor em uma interação social (Caballo, 2003). Certamente a habilidade de ouvir possui um lugar ainda de maior importância na profissão do psicólogo. Ouvir com atenção é importante para se obter informações sobre o interlocutor, que são necessárias para todo o processo de comunicação. Além disso, a escuta ativa envolve sinais verbais e não verbais de atenção, que produzem um efeito de incentivo na pessoa que está falando, estimulando-o a prosseguir e indicando o interesse do ouvinte. Há evidências de que a duração da fala das pessoas é maior quando seu interlocutor olha mais frequientemente e mais tempo para elas, enquanto as escuta (Bandeira, Barroso \& Reis, 2004; Milbrook \& Farrell,1986). Presume-se que esta habilidade seja desenvolvida em diversas disciplinas do curso de Psicologia, tais como as que se referem ao aprendizado das técnicas de entrevista psicológica, técnicas psicoterápicas e principalmente nos estágios curriculares supervisionados.

Destaca-se, também, no presente estudo, a importância atribuída à habilidade de recusar pedidos abusivos, que remete claramente ao comportamento assertivo, o qual consiste em uma das subclasses das habilidades sociais (Del Prette e Del Prette, 1999; Lange \& Jakubowsky, 1978). A importância da assertividade destaca-se ainda nos dois subgrupos de psicólogos, que possuíam menos e mais de 10 anos de atuação profissional, ao indicarem, dentre as quatro habilidades mais importantes, o comportamento assertivo de "Dizer não a solicitações que ele não pode atender" e de "Mostrar firmeza nas decisões tomadas", respectivamente. A capacidade de dizer não aparece também como uma das mais importantes pelo subgrupo de psicólogos que possuía pós-graduação. Entretanto, apesar do destaque dado à assertividade, é difícil presumir quais atividades curriculares do curso de Psicologia poderiam promover esta habilidade, exceto talvez, em estágios curriculares supervisionados. Além disso, a habilidade de observar, com atenção, as expressões relevantes do interlocutor se destacam 
também, no presente trabalho, dentre as mais importantes para a atuação profissional em Psicologia.

É interessante notar que as duas habilidades mais destacadas nos resultados da presente pesquisa - observar e ouvir - remetem às competências e habilidades básicas citadas nas Diretrizes Curriculares do MEC (CNE, 2004), para compor o núcleo comum do curso de Psicologia. De fato, estas duas habilidades constituem em componentes da entrevista e da observação, que figuram entre as competências a serem focalizadas nas disciplinas e nos estágios básicos do curso de Psicologia. Os resultados da presente pesquisa vêm corroborar, portanto, as diretrizes curriculares, com os dados da opinião de psicólogos atuantes em sua profissão.

A habilidade de ajudar o outro a identificar seus sentimentos, que também aparece dentre as quatro mais destacadas do presente trabalho, remete mais particularmente ao contexto de aplicação da Psicologia Clínica. Este resultado pode, talvez, ser explicado pelo fato da amostra ser predominantemente de psicólogos da área clínica.

Os psicólogos da presente amostra relataram possuir domínio de grande número das habilidades de comunicação estudadas aqui, em particular aquelas que foram consideradas como as mais importantes. Entretanto, seu grau de domínio estimado ficou, em geral, significativamente abaixo do grau de importância atribuída por eles a estas habilidades. Estes resultados corroboram os dados obtidos no estudo de Del Prette e cols. (2000), onde o grau de domínio relatado pelos psicólogos também foi inferior ao grau de importância que atribuíam às habilidades interpessoais. Estes resultados podem sugerir uma subestimação das próprias habilidades, uma preocupação de estar sempre se suplantando na atuação profissional ou, por outro lado, uma constatação real de um repertório de habilidades de comunicação aquém do desejado, o que remete à necessidade de maior investimento na formação dos profissionais no curso de Psicologia, com relação a estas habilidades.

Independentemente da orientação teórica adotada pelos psicólogos, algumas habilidades de comunicação interpessoal foram igualmente valorizadas por todos. Foi o caso das habilidades de ouvir e de observar. Este resultado demonstra como são fundamentais estas duas habilidades, que devem, portanto, receber uma atenção especial nos estágios básicos do curso de Psicologia, os quais visam desenvolver competências e habilidades comuns às diversas abordagens e às diferentes áreas de atuação em Psicologia.
Entretanto, as especificidades das diferentes abordagens teóricas em Psicologia também se fizeram notar, nos resultados obtidos no presente trabalho. Os psicólogos de abordagem psicanalítica, por exemplo, destacaram a habilidade de interpretar a fala do outro. No caso dos psicólogos de abordagem humanista, houve destaque para a habilidade de ajudar o outro a identificar e expressar sentimentos. Os que se designaram como ecléticos também enfatizaram a habilidade de ajudar a identificar e expressar sentimentos, mas incluíram ainda a habilidade de observar expressões não-verbais relevantes. Por outro lado, os psicólogos de abordagem comportamental ou cognitivo-comportamental destacaram a habilidade de se auto-observar e reavaliar as decisões e atitudes tomadas.

Os resultados obtidos no presente trabalho mostraram, portanto, que as habilidades sociais profissionais, necessárias à comunicação interpessoal, na opinião dos psicólogos, são importantes para a sua atuação profissional. Os resultados destacam a necessidade de dar maior atenção à formação e desenvolvimento destas habilidades no curso de Psicologia, através dos estágios curriculares básicos e profissionalizantes e das atividades complementares. Esses resultados limitam-se a uma amostra de profissionais predominantemente da área clínica, o que pode direcionar a importância atribuída às habilidades de comunicação interpessoal. Pesquisas futuras, com amostras mais amplas de várias áreas de atuação da Psicologia e de várias abordagens teóricas diferentes, poderão detalhar, de forma mais precisa, as especificidades e pontos comuns entre estas vertentes. Além disso, a utilização de instrumentos de medida padronizados em pesquisas futuras poderiam fornecer dados mais detalhados, referentes a diferenças entre subgrupos de profissionais em relação a fatores ou sub-escalas das habilidades sociais investigadas

\section{REFERÊNCIAS}

Bandeira, M., Barroso, S. M. \& Reis, F. V. (2004). Desempenho social de psicóticos em função do comportamento do interlocutor em interações sociais. Interação em Psicologia, $8(2), 247-259$.

Bandeira, M., Quaglia, M. A. C., Souza, A. C. \& Magalhães, F. C. (2003). Habilidades sociais de estudantes universitários: elaboração de uma escala de avaliação através de desempenho de papéis. Em Sociedade Brasileira de Psicologia (Org.), Anais da XXXIII Reunião Anual de Psicologia (p. 338). Belo Horizonte: SBP.

Bandeira, M. \& Quaglia, M. A. C. (2005). Habilidades sociais de estudantes universitários: identificação de situações sociais significativas. Interação em Psicologia, 9(1), 45-55.

Interação em Psicologia, Curitiba, jan./jun. 2006, (10)1, p. 139-149 
Bryant, B. \& Trower, P. E. (1974). Social difficulty in student sample. British Journal of Educacional Psychology, 44, 13-21.

Caballo, V. E. (1996). Manual de técnicas de terapia e modificação do comportamento. São Paulo: Livraria Santos Editora.

Caballo, V. E. (2003). Manual de avaliação e treinamento das habilidades sociais. São Paulo: Livraria Santos Editora.

CNE (2004). Diretrizes Curriculares Nacionais para os Cursos de Graduação em Psicologia. Documento emitido pelo Conselho Nacional de Educação, Câmara de Educação Superior, na Resolução $n^{\circ}$ 8, de 7 de maio de 2004.

Del Prette, A. (1978). O treino assertivo na formação do psicólogo. Arquivos Brasileiros de Psicologia Aplicada, 30, 5355.

Del Prette, A., Del Prette, Z. A. P. \& Correia, M. F. B. (1992). Competência social: um estudo comparativo entre alunos de psicologia, serviço social e engenharia mecânica. Psicólogo Escolar: Identidade e Perspectivas, 382-384.

Del Prette, A., Del Prette, Z. A. P. \& Castelo Branco, U. V. (1992a). Competência social na formação do psicólogo. Paidéia:Cadernos de Educação, 2, 40-50.

Del Prette, A. \& Del Prette, Z. A. P. (2003). No contexto da travessia para o ambiente de trabalho: treinamento de habilidades sociais com universitários. Estudos de Psicologia, 8(3), 413-420.

Del Prette, Z. A. P. \& Del Prette, A. (1999). Psicologia das habilidades sociais: terapia e educação. Rio de Janeiro: Vozes.

Del Prette, Z. A. P., Del Prette, A. \& Castelo Branco, U. V. (1992b). Competência social: um levantamento de situações críticas de interação para estudantes de Psicologia. Psicólogo Escolar: Identidade e Perspectivas, 384-387.

Del Prette, Z. A. P., Del Prette, A., Abraham, L. J. \& Reis, M. J. D. (2000). Desempenho interpessoal do profissional de psicologia: um estudo preliminar. Trabalho não publicado, Universidade Federal de São Carlos, São Carlos, SP.

Del Prette, Z. A. P. \& Del Prette, A. (2001). Psicologia das relações interpessoais: Vivências para o trabalho em grupo. Petrópolis: Editora Vozes.

Falcone, E. (2003). Habilidades sociais do terapeuta cognitivocomportamental na interação com pacientes difíceis. Em A. Del Prette \& Z. A. P. Del Prette (Orgs.), Habilidades Sociais, Desenvolvimento e Aprendizagem (pp.147-164). Campinas: Editora Alínea.

Lange, A. J. \& Jakubowski, P. (1978). Responsible assertive behavior. Illinois: Research Press Co.

Milbrook, J. M. \& Farrell, A. D. (1986). Behavioral components of social skills: a look at subject and confederate behaviors. Behavior Assessement, 8, 203-220.

Ouellet, R. \& L'Abbé, Y. (1986). Programme d'entraînement aux habiletés socials. Brossard: Éditions Behaviora.

Segrin, C. \& Flora, J. (2000). Poor social skills are a vulnerability factor in the development of psychosocial problems. Human Communication Research, 2 (3), 489-514.

Recebido: 25/05/2005

Revisado: 02/11/2005

Aceito: 03/06/2006

\section{Sobre os autores:}

Marina Bandeira, Ph.D.: Professora Adjunta da Universidade Federal de São João del Rei. Pesquisadora-bolsista do CNPq. Pósdoutorado pela McGill University e Université de Montréal.

Maria Amélia Cesari Quaglia: Professora Assistente da Universidade Federal de São João del Rei. Mestre pela Universidade de São Paulo (Ribeirão Preto). Doutoranda pela Universidade de São Paulo (Ribeirão Preto).

Lucas Cordeiro Freitas: Aluno do curso de graduação de Psicologia da Universidade Federal de São João del Rei. Bolsista de Iniciação Científica do CNPq.

Amanda Monteiro de Sousa: Aluna do curso de graduação de Psicologia da Universidade Federal de São João del Rei.

Andréa Luciane Pires Costa: Aluna do curso de graduação de Psicologia da Universidade Federal de São João del Rei.

Marcela Mansur Pires Gomides: Aluna do curso de graduação de Psicologia da Universidade Federal de São João del Rei.

Pedro Baratti Lima: Aluno do curso de graduação de Psicologia da Universidade Federal de São João del Rei.

Endereço para correspondência: Marina Bandeira - Laboratório de Pesquisa em Saúde Mental - LAPSAM <www.lapsam.ufsj.edu.br> - Departamento de Psicologia - UFSJ - Praça Dom Helvécio, 74, Bairro Fábricas - 36301-160 São João del Rei/MG - Endereço eletrônico: bandeira@ufsj.edu.br. 